\title{
DOS NUEVAS DIRECTIVAS DE LA UNIÓN EUROPEA \\ EN MATERIA SOCIAL: DESPLAZAMIENTO TEMPORAL DE TRABAJADORES Y TITULACIONES PROFESIONALES
}

\author{
Joaquín GarCía MurCia \\ Dpto. Derecho del Trabajo y de la Seguridad Social \\ Facultad de Derecho. Universidad Complutense de Madrid \\ jgmurcia@der.ucm.es
}

\section{BREVE PRESENTACIÓN}

La Unión Europea ha aprobado recientemente dos nuevas directivas en materia social. Por un lado, la Directiva (UE) 2018/957, de 28 de junio de 2018, que lleva a cabo una importante reforma de la Directiva 96/71/CE, de 16 de diciembre de 2018, sobre desplazamiento de trabajadores efectuado en el marco de una prestación de servicios, que ya había sido completada y reforzada por la Directiva 2014/67/UE, de 15 de mayo de 2014, y que en alguna medida había sido afectada por la Directiva 2008/104/ CE, de 19 de noviembre de 2008, sobre empresas de trabajo temporal. Por otro lado, la Directiva UE 2018/058, también de 28 de junio de 2018, relativa al test de proporcionalidad que deben observar los Estados miembros antes de adoptar nuevas normas sobre titulaciones profesionales, que viene a completar y desarrollar las reglas de armonización y coordinación que en esta otra materia dispuso en su momento la Directiva 2005/36/CE, de 7 de septiembre de 2005. Son dos nuevas pruebas de que, frente a la sensación de parálisis que a veces parece transmitirse, la actividad legislativa de la Unión Europea en el terreno del empleo y las relaciones de trabajo no ha dejado de producir resultados. Es evidente que su ritmo no es equiparable al de los años noventa, quizá los más fructíferos en este sentido, pero también es claro que la Unión no se ha olvidado ni de sus objetivos en materia social ni de los encargos o compromisos que, por uno u otro motivo, tenía que cumplimentar en algunas parcelas de su sistema normativo relativas al ámbito laboral o profesional. 


\section{EL NUEVO RÉGIMEN COMUNITARIO PARA EL DESPLAZAMIENTO TEMPORAL DE TRABAJADORES}

1. A diferencia de la Directiva 2014/67/UE, que supuso la apertura de un cauce normativo que actúa en paralelo a la Directiva 97/71/CE y que, sin llegar a trastocarla, pretende reforzar y garantizar la efectividad de sus mandatos, la Directiva 2018/957 (DOUE de 9 de julio de 2018) ha procedido a la modificación y reestructuración de buena parte de los preceptos de esta última con el propósito de solventar algunas de las deficiencias o insuficiencias que se habían advertido en su experiencia aplicativa, en muchos casos a raíz de la interpretación ofrecida por el Tribunal de Justicia con ocasión de diversas reclamaciones empresariales basadas en las libertades económicas reconocidas por el Derecho comunitario. Sin perjuicio de otros asuntos de menor impacto o visibilidad, la reforma ha tratado de hacer frente, sobre todo, a dos de los problemas que con mayor empeño se venían aireando con ocasión de la deslocalización de empresas y del desplazamiento temporal de trabajadores de unos países a otros en el espacio comunitario en el contexto del ejercicio de las libertades de prestación de servicios: la preservación de los derechos de acción colectiva (de reivindicación, de presión, de negociación, etc.) de quienes pudieran verse envueltos o afectados por esas prácticas empresariales, y la garantía de un nivel apropiado de condiciones de trabajo para los trabajadores desplazados de un país a otro. Naturalmente, la Directiva 2018/957 sigue proclamando que la libre circulación de los trabajadores, la libertad de establecimiento y la libre prestación de servicios por parte de empresas y profesionales (de la que deriva, a fin de cuentas, el desplazamiento temporal de trabajadores) son principios fundamentales del mercado interior propio de la Unión Europea, y que tales principios deben entenderse y aplicarse de tal manera que se garantice la igualdad de condiciones para todas las empresas y el respeto de los derechos de los trabajadores, particularmente de los que son objeto de desplazamiento de un país a otro, no solo en lo que respecta a sus condiciones de trabajo, especialmente en materia salarial, sino también en lo que se refiere a sus condiciones de vida (alojamiento, manutención y gastos de viaje, por ejemplo). Se trata, en definitiva, de que los desplazamientos se efectúen en «condiciones equitativas» para todos los implicados y con observancia de los principios básicos del mercado interior. 
2. Probablemente uno de los pasajes que más llame la atención dentro de esta reforma de la Directiva 96/71/CE sea el que ahora figura en el punto 1 bis del art. 1 de dicho texto, añadido precisamente por la Directiva 2018/957. Y es así porque en esa nueva regla se hace una muy significativa declaración formal para advertir, como ya había hecho, por cierto, la Directiva 2014/67/UE, que estas normas comunitarias sobre desplazamiento temporal de trabajadores no afectarán en modo alguno «al ejercicio de los derechos fundamentales reconocidos en los Estados miembros y a escala de la Unión, incluyendo el derecho o la libertad de huelga o de emprender otras acciones contempladas en los sistemas de relaciones laborales específicos de los Estados miembros, de conformidad con la legislación o las prácticas nacionales»; con la precisión de que tampoco afectarán «al derecho a negociar, concluir y hacer cumplir convenios colectivos o llevar a cabo acciones colectivas conforme a la legislación o las prácticas nacionales». En una simple aproximación, tal declaración puede parecer obvia e incluso prescindible, habida cuenta que las normas que regulan los desplazamientos de trabajadores con ocasión del ejercicio de la libre prestación de servicios por parte de las empresas ni crean ni tienen como objetivo crear un reducto ajeno a los derechos fundamentales, ni siquiera a los derechos laborales ordinarios. Más bien se trata de instrumentos encaminados a la protección de los trabajadores que, por tal condición, se unen a las garantías que proporcionan todos esos derechos. Pero desde las sentencias Viking y Laval del Tribunal de Justicia, ambas de 2007, se venía pidiendo una toma de posición expresa por parte del legislador comunitario a ese respecto no tanto para dejar a salvo este particular segmento normativo como para dar a entender que la defensa de los intereses empresariales implicados en esta clase de operaciones o iniciativas económicas no debe significar en ningún caso merma de los derechos de los trabajadores, particularmente de los derechos de libertad sindical y acción colectiva. Si bien se mira, ni una declaración formal en ese sentido era estrictamente necesaria ni la situación real de los trabajadores cambia por ese solo hecho, pero seguramente la nueva regla aporta algunas dosis de tranquilidad en el contexto de unas relaciones (entre las libertades económicas y los derechos laborales de acción colectiva) que no siempre parecen entenderse de manera correcta, tal vez por su alto grado de exposición a la lucha de intereses y al análisis ideológico.

3. Otra modificación relevante es la que se ha producido en el art. 3 de la Directiva 96/71/CE, relativo a las condiciones de trabajo aplicables a los trabajadores desplazados en el Estado «de acogida». Según la nueva 
redacción del precepto, que eleva de manera apreciable el nivel de protección de su versión original, los Estados miembros deben cuidar de que, dentro de su territorio y sobre la base de la igualdad de trato, las empresas garanticen a los trabajadores desplazados temporalmente las condiciones de trabajo establecidas no solo en las pertinentes disposiciones legales o reglamentarias y en los convenios colectivos o laudos arbitrales declarados «de aplicación universal», sino también en los convenios colectivos o laudos «de cualquier otro modo de aplicación». Esta precisión, que se reitera más adelante (en el art. 3) para los desplazamientos de duración superior a doce meses, supone que, a partir de esta nueva redacción, la Directiva 96/71/CE exige no solo la aplicación de las condiciones establecidas para el correspondiente lugar de trabajo por un convenio colectivo dotado de «eficacia general», sino también, en su caso, las condiciones establecidas por cualquier otro convenio colectivo, aunque no tenga esa capacidad de regulación. Con ello, la reforma de 2018 quiere dar respuesta a otro de los problemas puestos de relieve por algunos pronunciamientos del Tribunal de Justicia (en la sentencia Rüffert, por ejemplo), en tanto que a veces la actividad acometida por los trabajadores desplazados está regulada, al menos en el ámbito local o comarcal de referencia, no ya por convenios generales, o no solo por convenios generales, sino más bien o más directamente por convenios colectivos que tienen un ámbito funcional más particular o localizado (por ejemplo, el convenio colectivo celebrado por una organización sindical con la empresa contratante, que en muchas ocasiones es, por cierto, una entidad pública). Sin embargo, la identificación de ese tipo de convenios no es fácil y la reforma de 2018 no da muchas pistas al respecto. Ni siquiera se ha cuidado de facilitar esa tarea al abordar la modificación del apartado 8 de su art. 3, pese a que en dicho precepto, desde la redacción original de la Directiva 96/71/CE, se han venido dando, y se siguen dando, algunas indicaciones acerca de los convenios colectivos a los que los Estados miembros pueden remitir para el cumplimiento de estas directrices de armonización.

4. Innovación significativa de la Directiva 2018/957 es, asimismo, la que afecta al elenco de condiciones de trabajo que deben observarse en el territorio «de acogida» en caso de desplazamiento temporal de trabajadores. Ya sabemos que, en principio, son las condiciones establecidas por disposiciones legales o convenios colectivos, pero con la Directiva 2018/957 se introducen dos novedades a la hora de precisar el alcance material de esa remisión: por una parte, se amplían las condiciones respecto de las que juega con carácter general la regla de equiparación con el 
lugar de trabajo; por otra, se traza una importante línea de separación en función de la duración del desplazamiento, a la que después aludiremos. Para desplazamientos de duración inferior a ese límite temporal, que probablemente sean los más frecuentes, sigue rigiendo la regla tradicional de especificación de las condiciones de trabajo sometidas al deber de equiparación, lo cual, como es fácil de comprender, puede implicar en el fondo alguna clase de limitación y algún margen de diferencia entre el trabajador «local» y el trabajador desplazado. Pero el acervo de condiciones respecto de las que debe jugar la equiparación, que ya era bastante extenso, se amplía notablemente con la reforma de 2018, particularmente en lo que se refiere al salario y, en general, a la materia económica. Por lo pronto, la equiparación no solo rige para la cuantía del salario mínimo, sino más estrictamente para el conjunto de la remuneración, en la que, sin perjuicio de que su definición o alcance concreto correspondan a «la legislación o las prácticas nacionales del Estado miembro en cuyo territorio esté desplazado el trabajador», deberán comprenderse «todos los elementos constitutivos de la remuneración obligatorios en virtud de las disposiciones legales, reglamentarias o administrativas nacionales o de los convenios colectivos o los laudos arbitrales que en dicho Estado miembro hayan sido declarados de aplicación universal o de cualquier otro modo de aplicación» (según la fórmula que ya conocemos). Además, la regla de equiparación se extiende a conceptos que pueden tener naturaleza no salarial e incluso a condiciones que ya no son estrictamente de trabajo: de un lado, a los complementos o los reembolsos en concepto de gastos de viaje, alojamiento y manutención en aquellos casos en que los trabajadores desplazados «deban viajar a y desde su lugar habitual de trabajo situado en el Estado miembro en cuyo territorio estén desplazados» o «cuando su empleador los envíe temporalmente desde dicho lugar habitual de trabajo a otro lugar de trabajo», aclaración esta que ya estaba en la versión original de esta norma comunitaria pero que, tras la reforma de 2018, adquiere un tono más protector para el trabajador; de otro, a «las condiciones de alojamiento de los trabajadores, cuando el empleador se las proporcione a trabajadores que se encuentren fuera de su lugar de trabajo habitual». Mayor aún es la equiparación en los desplazamientos que superan los doce meses (periodo que los Estados deberán extender a dieciocho meses en determinadas condiciones), pues en tal supuesto alcanza a «todas las condiciones de trabajo» establecidas en el Estado miembro en el que se efectúe la prestación de servicios, si bien de esta regla general se exceptúan, seguramente porque ya no se trata de condiciones laborales en 
sentido estricto, «los procedimientos, formalidades y condiciones de celebración y de resolución del contrato de trabajo» y los «regímenes complementarios de jubilación».

5. La Directiva 2018/957 incluye algunas otras reglas de variada naturaleza, buena parte de ellas de carácter instrumental, ligadas casi siempre al buen fin de los deberes de transposición impuestos a los Estados miembros de la Unión. En ese sentido cabe citar, en primer término, las previsiones específicamente dirigidas a los desplazamientos temporales de trabajadores desde empresas de trabajo temporal hacia empresas usuarias de otro país, supuesto para el que la Directiva 2018/957 impone reglas específicas de información y de equiparación de condiciones de trabajo, entre otras razones por la incidencia de la Directiva 2008/104/CE; reglas que, por cierto, también se aplican a las «agencias de colocación» cuando aquellas sean titulares de la correspondiente relación laboral (hipótesis bastante extraña al sistema español, dicho sea de paso). También cabe citar el notable refuerzo de las funciones de vigilancia, control y ejecución asignadas a los Estados miembros, que no solo deben velar por la efectiva aplicación de estas reglas mediante la imposición de sanciones por incumplimiento y la apertura de procedimientos adecuados de reclamación, sino que también deben evitar que las empresas creen de manera indebida o fraudulenta «la impresión de que la situación de un trabajador entra en el ámbito de aplicación» de estas normas comunitarias. En fin, los Estados miembros deben proceder a la transposición de esta nueva Directiva a más tardar el 30 de julio de 2020 y la Comisión Europea, por su parte, debe elaborar un informe de aplicación a más tardar el 30 de julio de 2023 en el que deberán proponerse en su caso las modificaciones necesarias «de la presente Directiva y de la Directiva 96/71/CE», y en el que deberá figurar una evaluación de la necesidad de adoptar nuevas medidas para garantizar condiciones de competencia equitativas y proteger a los trabajadores en relación con los supuestos de subcontratación y con la actividad de transporte por carretera, que de momento se mantiene excluida pero que, a tenor de estas mismas previsiones, podría ser incorporada a este acervo normativo mediante la proyectada reforma de su regulación específica (la Directiva 2006/22/CE). 


\section{EL TEST DE PROPORCIONALIDAD EN LA REGULACIÓN NACIONAL DE LAS TITULACIONES PROFESIONALES}

1. La Directiva UE 2018/958 (DOUE de 9 de julio de 2018) tiene por objeto, como ya dijimos, precisar el alcance del «test de proporcionalidad» que deben observar los Estados miembros de la UE al ejercer sus competencias de regulación de las titulaciones profesionales, con el fin último de garantizar en el mercado interior la libertad profesional, calificada explícitamente por este mismo texto como «derecho fundamental». Muy oportunamente, el preámbulo de la Directiva 2018/958 recuerda que, a tenor de la jurisprudencia del Tribunal de Justicia y en virtud precisamente del principio de proporcionalidad (al que de manera inevitable hay que añadir el de no discriminación), «las medidas nacionales que puedan obstaculizar o hacer menos atractivo el ejercicio de las libertades fundamentales garantizadas por el TFUE deben cumplir cuatro requisitos: que se apliquen de manera no discriminatoria, que estén justificadas por objetivos de interés público, que sean adecuadas para garantizar la realización del objetivo que persiguen y que no vayan más allá de lo necesario para alcanzar dicho objetivo». Son exigencias que tienen proyección general sobre todas aquellas medidas que puedan afectar a ese elenco de libertades básicas de la Unión y que juegan de manera especialmente intensa en algunos ámbitos, entre los que se encuentra sin duda alguna el relativo al acceso de los profesionales a la actividad que les es propia a lo largo y ancho del espacio comunitario. Como también recuerda el preámbulo de la Directiva 2018/958, esas exigencias ya estuvieron presentes en la Directiva 2005/36/CE a la hora de aprobar directrices para el reconocimiento de cualificaciones profesionales en el territorio de la Unión, pues ya en ese momento se introdujo la obligación de los Estados miembros «de evaluar la proporcionalidad de los requisitos que limitan el acceso a las profesiones reguladas o su ejercicio y de comunicar a la Comisión los resultados de esa evaluación». Un proceso de «evaluación recíproca» que, según esas mismas fuentes, reveló falta de claridad, «así como un examen desigual de dichos requisitos en todos los niveles de regulación», y que motivó, a fin de cuentas, la aprobación de la Directiva 2018/958. El detonante más directo de esta nueva norma comunitaria fue de todas formas una Comunicación presentada por la Comisión Europea con fecha de 28 de octubre de 2015 en la que, bajo el título de «Mejorar el mercado único: más oportunidades para los ciudadanos y las empresas», se advertía sobre «la necesidad de adoptar un marco 
analítico de proporcionalidad para su utilización por parte de los Estados miembros cuando revisen las regulaciones existentes de las profesiones o propongan otras nuevas». Como es de rigor, la Directiva 2018/658 insiste en los fines típicamente comunitarios de evitar la fragmentación del mercado interior y de eliminar las barreras de acceso a las actividades profesionales de referencia, ya sea para ejercitarlas por cuenta propia ya sea para hacerlo por cuenta ajena.

2. En ese contexto y con esos objetivos, la Directiva 2018/958 establece «normas relativas a un marco común para efectuar evaluaciones de proporcionalidad antes de introducir nuevas disposiciones legales, reglamentarias o administrativas que restrinjan el acceso a las profesiones reguladas o su ejercicio, o de modificar las existentes, con vistas a garantizar el buen funcionamiento del mercado interior, a la vez que se garantiza un nivel elevado de protección de los consumidores», en el bien entendido de que ni obliga a los Estados miembros a regular las profesiones ni predetermina la manera en que en su caso debieran hacerlo, sin perjuicio de la necesidad que en todo caso tienen los ordenamientos nacionales de atenerse a los límites que se derivan de los principios de no discriminación y proporcionalidad (art. 1). La Directiva 2018/958 se aplica «a las disposiciones legales, reglamentarias o administrativas de los Estados miembros que restringen el acceso a una profesión regulada o su ejercicio, o una de sus modalidades de ejercicio, como puede ser el uso de títulos profesionales y las actividades profesionales permitidas en virtud de dicho título», siempre que tales títulos y actividades entren en el ámbito de aplicación de la Directiva 2005/36/CE (art. 2.1). No se aplica, en cambio, en aquellos supuestos en los que «un acto específico de la Unión» imponga «requisitos específicos relativos a la regulación de una profesión determinada que no permitan a los Estados miembros elegir el modo exacto de transponerlos» (art. 2.2). Por lo demás, y con ese mismo propósito de delimitar con la mayor precisión posible su radio de acción, la Directiva 2018/958 añade dos definiciones al listado de la Directiva 2005/36/CE con el fin de facilitar, dentro de los objetivos de «armonización», la tarea nacional de regulación de las titulaciones y actividades profesionales: la definición de «título profesional protegido», aplicable a aquellos títulos que son necesarios para el ejercicio de una actividad profesional o grupo de actividades profesionales, que tienen relación con una cualificación profesional específica y que están garantizados por un sistema de sanciones en caso de uso indebido, y la definición de «actividades reservadas», que son aquellas actividades profesionales o grupos de actividades profesionales en las que el acceso 
puede quedar efectivamente reservado a miembros de una profesión regulada con una cualificación profesional específica, «incluidos los casos en los que la actividad se comparte con otras profesiones reguladas» (art. 3).

3. El contenido de la Directiva 2018/958 puede sintetizarse en una serie de obligaciones que la Unión Europea impone a los Estados miembros cuando ejerciten sus competencias de regulación de las profesiones y de los correspondientes títulos profesionales y, en particular, antes de introducir nuevas disposiciones legales, reglamentarias o administrativas, o de modificar las existentes, que restrinjan el acceso a las profesiones reguladas o el ejercicio de las mismas. Las obligaciones a las que nos referimos son las siguientes: la obligación de llevar a cabo «una evaluación de la proporcionalidad», una evaluación que debe realizarse de manera objetiva e independiente, que debe ajustarse a «las normas establecidas en la presente Directiva» y que debe ir acompañada de una explicación suficientemente detallada que permita valorar el cumplimiento del principio de proporcionalidad (art. 4); la obligación de observar el principio de no discriminación por motivos de nacionalidad o residencia (art. 5); la obligación de aportar una justificación basada en motivos de orden público o de seguridad o salud públicas o en «razones imperiosas de interés general», como la preservación del equilibrio financiero del régimen de seguridad social o la protección de los trabajadores, entre otras (art. 6); la obligación de seguir el principio de proporcionalidad en los correspondientes procedimientos legislativos, cuidando siempre de que las restricciones «sean necesarias y adecuadas para garantizar la consecución del objetivo perseguido y no vayan más allá de lo necesario para alcanzarlo», conforme a las pautas e indicaciones que aporta a tal efecto la propia Directiva 2018/958 (art. 7), y, finalmente, la obligación de informar a «los ciudadanos, destinatarios de servicios y otros interesados, incluidos quienes no sean miembros de la profesión de que se trate»; una obligación que va acompañada a su vez de otros dos deberes complementarios: el de dar a esos grupos la oportunidad de «manifestar sus opiniones» y el de llevar a cabo «consultas públicas» cuando sea pertinente y adecuado de conformidad con los procedimientos de cada país (art. 8). La Directiva 2018/958, que entra en vigor a los veinte días de su publicación oficial, debe ser traspuesta a los ordenamientos nacionales «a más tardar el 30 de julio de 2020» (art. 13). 